\title{
Thermodynamics of Metal Complex Formation in Aqueous Solution. II. A Calorimetric Study of Fluoride Complexes of Hydrogen, Uranium(VI), and Vanadium(IV)
}

\author{
STEN AHRLAND and LENNART KULLBERG \\ Inorganic Chemistry 1, Chemical Center, University of Lund, P.O.B. 740, \\ S.220 07 Lund 7, Sweden
}

The enthalpy changes for the formation of hydrogen, uranyl(VI), and vanadyl(IV) fluoride complexes have been determined by a direct calorimetric titration procedure. From these enthalpy changes and the changes in free energy computed from the corresponding stability constants ${ }^{1}$ the entropy changes have been calculated from the relationship:

$$
\Delta G_{j}^{\circ}=\Delta H_{j}{ }^{\circ}-T \Delta S_{j}{ }^{\circ}
$$

All data refer to $25.00^{\circ} \mathrm{C}$ and an aqueous sodium perchlorate medium of ionic strength $1.00 \mathrm{M}$.

In the fluoride systems studied, nearly all the species are formed in endothermic reactions. The strong complex formation for these systems thus depends upon the large gains of entropy involved.

A pointed out in part I of this series, ${ }^{1}$ it is necessary to determine both the
reaction in order the entropy information about the nature of the bond formation
the work described here, the enthalpy changes for the formation of fluoride
complexes of the hard acceptors uranyl(VI) and vanadyl(IV) have been deter-
mined. From these data, and the stability constants measured previously,
the entropy changes are calculated according to:

$$
\Delta G_{j}^{\circ}=\Delta H_{j}^{\circ}-T \Delta S_{j}^{\circ}
$$

All quantities necessary for a discussion of the factors governing the formation of these complexes are then known.

Enthalpy changes can be determined either by measuring the stability constants as a function of the temperature, or by direct calorimetric measurements. With the first method the enthalpy change is obtained from the slope

Acta Chem. Scand. 25 (1971) No. 9 
of $\log K$ as a function of $T^{-1}$, provided that the change of heat capacity, $\Delta C_{p}$, is negligible within the range of $T$ used. If this does not apply the graphs show an appreciable curvature. Even if the conditions are fulfilled, however, very precise measurements of $K$ over a wide range of $T$ are demanded if the values of $\Delta H$ obtained by the temperature coefficient method are to be as reliable as those obtained by calorimetry.2,3

The calorimetric measurements are most conveniently arranged as titrations which permit the collection of a large number of data with a reasonable amount of effort. ${ }^{4}$ To simplify the conditions, the hydrolysis of the metal ions has been suppressed by the addition of perchloric acid. As a consequence, proton as well as metal fluoride complexes were formed during the calorimetric experiments. In order to find the heat changes referring to the formation of metal fluoride complexes, those due to the formation, or disruption, of proton complexes had to be known. They were found from a separate investigation of the hydrogen fluoride system.

The stability constants of the systems have to be known not only for the calculation of the entropy term, according to eqn. (1), but also for the calculation of the compositions of the solutions obtained during the calorimetric titrations. The values of $\beta_{j}$ used are collected in Table 5 .

No direct calorimetric determination of the enthalpy changes of the uranyl(VI) and vanadyl(IV) fluoride complex formation has been published so far. Day and Powers ${ }^{5}$ have studied the uranyl fluoride system by an extraction method and they have determined the stability constants at 10 , 25 , and $40^{\circ} \mathrm{C}$ at an ionic strength of $2.00 \mathrm{M}$ with $\mathrm{NaClO}_{4}$ as the supplementary neutral salt. From the values found, they calculated $\Delta H_{1}^{\circ}$ to be about $-10 \mathrm{~kJ}$ $\mathrm{mol}^{-1}$. The hydrogen fluoride system has been investigated by calorimetric measurements by Hepler et al. ${ }^{6}$ They obtained a value of $\Delta H_{1}^{\circ}=13.3 \mathrm{~kJ} \mathrm{~mol}^{-1}$ at infinite dilution and $25.0^{\circ} \mathrm{C}$. From a compilation of apparently reliable values of $K_{1}$ in the temperature range $0-50^{\circ} \mathrm{C}$, a value of $\Delta H_{1}^{\circ}=12.2 \mathrm{~kJ}$ mol $^{-1}$ has been calculated ${ }^{7}$ for an ionic strength $0.5 \mathrm{M}$.

All measurements in this study have been carried out at $25.00^{\circ} \mathrm{C}$ in an aqueous medium of an ionic strength $I=1.00 \mathrm{M}$ with sodium perchlorate as supplementary electrolyte.

\section{NOTATION AND GENERAL EQUATIONS}

The notation is the same as in part $I$ of this series with the following additions:

$\Delta R=$ change in resistance after addition of titrant

$Q_{\exp }=$ corresponding heat change ( $>0$ if heat is evolved)

$Q_{\text {dil }}=$ heat of dilution

$Q_{\text {corr }}^{\prime}=Q_{\text {exp }}-Q_{\text {dil }}=$ heat change corrected for heat of dilution

$Q_{\text {corr }}=$ heat change corrected for both heat of dilution and heat effects due to the formation or disruption of proton complexes

$V_{0}=$ initial volume $\left(\mathrm{cm}^{3}\right)$ of the solution in the calorimeter vessel

$v=$ volume $\left(\mathrm{cm}^{3}\right)$ of titrant added

$V \quad=$ total volume $\left(\mathrm{cm}^{3}\right)$ of the solution in the calorimeter vessel 
$\varepsilon_{V}=$ heat equivalent $\left(\mathrm{J} \mathrm{ohm}^{-1}\right)$ of the calorimeter system at the volume $V$ $\Delta h_{v}=-\sum_{v} \frac{1000 Q_{\text {corr }}}{C_{\mathrm{M}} V}=$ total molar heat change after addition of $V$ $\Delta G_{j}^{\circ}=$ free energy change in the standard state for the step $j$ $\Delta H_{j}^{\circ}=$ enthalpy change in the standard state for the step $j$ $\Delta S_{j}^{\circ}=$ entropy change in the standard state for the step $j$

All the concentrations are given in molarity units (M) and all heat quantities in absolute joule.

The quantity $\Delta h_{v}$ is related to the stepwise enthalpy changes according to

$$
\Delta h_{v}=\sum_{j=1}^{N} \sum_{k=1}^{j} \alpha_{j} \Delta H_{k}^{\circ}
$$

where

$$
\alpha_{j}=\beta_{j}[\mathrm{~L}]^{j} / X
$$

Hence

$$
\Delta h_{v} X=\sum_{j=1}^{N} \sum_{k=1}^{j} \beta_{j}[L]^{j} \Delta H_{k}^{\circ}
$$

and

$$
\Delta h_{v} X /[\mathrm{L}]=\gamma_{1}([\mathrm{~L})]=\sum_{j=1}^{N} \sum_{k=1}^{j} \beta_{j}[\mathrm{~L}]^{j-1} \Delta H_{k}^{\circ}
$$

Extrapolation to $[\mathrm{L}]=0$ yields:

Generally

$$
\lim _{[\mathrm{L}] \rightarrow 0} \gamma_{1}([\mathrm{~L}])=\beta_{1} \Delta H_{1}^{\circ}
$$

$$
\begin{aligned}
\gamma_{n}([\mathrm{~L}])= & \left\{\gamma_{n-1}([\mathrm{~L}])-\lim _{[\mathrm{L}] \rightarrow 0} \gamma_{n-1}([\mathrm{~L}])\right\} /[\mathrm{L}]= \\
& =\sum_{j=n}^{N} \sum_{k=1}^{j} \beta_{j}[\mathrm{~L}]^{j-n} \Delta H_{k}^{\circ}
\end{aligned}
$$

and by extrapolation to $[\mathrm{L}]=0$

$$
\lim _{[\mathrm{L}] \rightarrow 0} \gamma_{n}([\mathrm{~L}])=\beta_{n} \sum_{k=1}^{n} \Delta H_{k}^{\circ}
$$

As the values of $\beta_{j}$ are known this procedure yields the total enthalpy change $\sum_{k=1}^{j} \Delta H_{k}^{\circ}$ up to and including the step $j$. Hence $\Delta H_{j}^{\circ}$ for each successive step can be calculated.

The function $\gamma_{1}([\mathrm{~L}])$ is obtained in the following way. The compositions of the solutions after each addition are determined from known values of $\beta_{j}, \delta_{j}, C_{\mathrm{M}}, C_{\mathrm{L}}$ and $C_{\mathrm{H}}$. The changes in the concentrations of proton complexes upon the addition of titrant are then calculated. With the $\Delta H_{j}^{\circ}$-values of protonation known, the heat effects arising from proton complex formation can then be calculated. Introducing the heats of dilution determined separately, $Q_{\text {corr }}$ is finally computed and hence $\Delta h_{v}$ (see above). Thus all quantities needed for the calculation of the function $\gamma_{1}([\mathrm{~L}])$ are available (cf. eqn. (5)).

Acta Chem. Scand. 25 (1971) No, 9 
As seen from eqn. (4), $\Delta h_{v}$ is a function of [L] only. If polynuclear complexes had been introduced, $\Delta h_{v}$ would depend also on [M] i.e. $C_{\mathrm{M}}$. Consequently it is possible to decide whether polynuclear complexes exist or not by performing titrations with different values of $C_{\mathrm{M}}$. Plots of $\Delta h_{v}$ versus $[\mathrm{L}]$ or $\bar{n}$, which is also a function of $[\mathrm{L}]$ only, ${ }^{1}$ will fall on the same curve if only mononuclear complexes are present in the solutions.

The enthalpy changes have also been calculated by a least squares computer program, "Letagrop Kalle", developed by Sillén et al.8,9 With this program, the computer searches for the set of values of unknown parameters, which will minimize the error square sum

$$
U=\sum_{i}\left(Q_{i, \text { corr, calc }}^{\prime}-Q_{i, \text { corr }}^{\prime}\right)^{2}
$$

The input data were the corresponding values of $Q_{\text {corr }}^{\prime}$ and $v$, the stability constants $\beta_{j}$ and $\delta_{j}$, the initial volume $V_{0}$ and the total concentrations of metal, hydrogen, and ligand in the $\mathrm{S}$ and $\mathrm{T}$ solutions.

The "Letagrop Kalle" calculations result in a set of enthalpy changes with their standard deviations and also the standard deviation $\sigma Q^{\prime}$ corr, in the quantity $Q_{\text {corr }}^{\prime}$. Moreover, the difference $\left(Q_{\text {corr,calc }}^{\prime}-Q_{\text {corr }}^{\prime}\right)$, denoted $\Delta Q_{\text {corr }}^{\prime}$ in the following, was given for each point.

\section{EXPERIMENTAL}

Chemicals. Hydrochloric acid and potassium hydroxide used for testing experiments were of analytical grade. The hydroxide solution was standardized against potassium biphthalate. All other chemicals used were prepared and analyzed as described before. ${ }^{1}$

Apparatus. The calorimeter used in this work is of the model developed and described by Grenthe et al.10 It is a titration calorimeter of the isothermal jacket type, with an inner vessel holding $120 \mathrm{~cm}^{3}$. In order to stand the acid fluoride solutions, this vessel is made of gold. For the same reason all other parts which are in contact with the solution (inlet and outlet tubes, stirrer, casings for heater and thermistor) are made of either gold or teflon (cf. Ref. 10).

The inner vessel is surrounded by an outer can which is wholly immersed in a thermostat bath of type LKB $7603 \mathrm{~A}$, maintained at $25.000 \pm 0.001^{\circ} \mathrm{C}$. During the time $(\approx \mathbf{4 5} \mathrm{min}$ ) required for the determination of the temperature change for one addition of titrant, the temperature was usually constant even to $\pm 0.0003^{\circ} \mathrm{C}$. The entire equipment is placed in a thermostated room where the temperature is kept within $25.0 \pm 0.2^{\circ} \mathrm{C}$.

The temperature change obtained for an addition of titrant or in a calibration experiment was measured with an estimated uncertainty of $\pm 5 \times 10^{-5}$ degrees, corresponding to $\pm 0.03 \mathrm{~J}$, by the use of a thermistor. The calorimeter was electrically calibrated. The time of equilibration ${ }^{10}$ of the system after heating and cooling, respectively, involving as much energy as $80 \mathrm{~J}$ was found to be 5 and $10 \mathrm{~min}$.

Procedure. During operation about $100 \mathrm{~cm}^{3}$ of a solution $S$ is first placed in the inner vessel and (by heating or cooling) given a temperature a little below that of the outer bath. By stirring the solution in the reaction vessel a smooth raising of its temperature is obtained. When the temperature is exactly the same as that of the outer bath, a portion (at most $4 \mathrm{~cm}^{8}$ ) of the titrant $T$ is added from a piston burette. On its way, T passes through a heat exchanger, placed in the thermostat. In order to ensure that the capacity of the heat exchanger is not exceeded, the addition is made at the slow rate of $1 \mathrm{~cm}^{3} / \mathrm{min}$. After reaction is completed, the solution is cooled, or heated, back to approximately its initial temperature, and the procedure is repeated.

Through the outlet tube, portions of the solution can also be removed. This has been done either before each addition (method A) of after the inner vessel has been almost completely filled (method B). 
In general, every titration series was carried out twice. The reproducibility was usually within $0.05 \mathrm{~J}$.

To determine the heats of dilution, series were performed with only one of the reacting components present. Thus the heats of dilution for the $\mathbf{S}$ solution were determined by additions of a $1.00 \mathrm{M} \mathrm{NaClO}$, solution to the $\mathrm{S}$ solution and the heats of dilution for the $\mathrm{T}$ solution were obtained by adding this solution to a S solution containing only $1.00 \mathrm{M}$ $\mathrm{NaClO}_{4}$.

Testing of the calorimeter. In order to test the accuracy of the calorimeter, the enthalpy changes of two well-investigated reactions have been determined, viz. the heat of dilution of hydrochloric acid and the heat of neutralization of a strong acid with a strong base.

In the first experiment, $2.002 \mathrm{M}$ hydrochloric acid was used. The reaction vessel was filled with $100.24 \mathrm{~cm}^{3}$ of water and the acid was added in $2.000 \mathrm{~cm}^{3}$ portions. The titrations were performed according to method A. The enthalpy changes refer to the process $\mathrm{HCl}, 26.7 \mathrm{H}_{2} \mathrm{O}+(n-26.7) \mathrm{H}_{2} \mathrm{O} \rightarrow \mathrm{HCl}, n \mathrm{H}_{2} \mathrm{O}$ where the values of $n$ are 1412 , 719 , and 488. The results, which are mean values of three series, are collected in Tuble 1 .

Table 1. Heats of dilution of $\mathrm{HCl}, 26.7 \mathrm{H}_{2} \mathrm{O}$ to $\mathrm{HCl}, n \mathrm{H}_{2} \mathrm{O}$ at $25^{\circ} \mathrm{C}$. At each addition $4.004 \times 10^{-3} \mathrm{~mol}$ is added. The $Q$-values are mean values of the observed heats of dilution for three series. The last column gives the corresponding $\Delta H$-values calculated from SVCTP. ${ }^{11}$

\begin{tabular}{|c|l|l|c|}
\hline$n$ & $Q / \mathrm{J}$ & $\frac{-\Delta H}{\mathrm{~kJ} \mathrm{~mol}^{-1}}$ & $\frac{-\Delta H_{\mathrm{calc}}}{\mathrm{kJ} \mathrm{mol}^{-1}}$ \\
\hline \multirow{3}{*}{1412} & $9.408 \pm$ & $2.350 \pm$ & \\
& 0.012 & 0.003 & 2.332 \\
719 & $8.268 \pm$ & $2.208 \pm$ & \\
& 0.014 & 0.003 & 2.203 \\
488 & $7.755 \pm$ & $2.117 \pm$ & \\
& 0.014 & 0.004 & 2.105 \\
\hline
\end{tabular}

In the last column the corresponding data calculated from SVCTP ${ }^{11}$ are given. The graphical evaluation of the SVCTP data is somewhat uncertain. In view of this, the agreement is quite satisfactory.

In the second experiment, $0.09855 \mathrm{M}$ potassium hydroxide was neutralized with $0.1004 \mathrm{M}$ hydrochloric acid. Four series were performed, with three additions of 2.000 $\mathrm{cm}^{3}$ in each. After correction for the heats of dilution, $-\Delta H_{\mathrm{w}} \infty=55.86 \pm 0.03 \mathrm{~kJ}$ $\mathrm{mol}^{-1}$ is obtained for the reaction $\mathrm{HCl}, \propto \mathrm{H}_{2} \mathrm{O}+\mathrm{KOH}, \infty \mathrm{H}_{2} \mathrm{O} \rightarrow \mathrm{KCl}, \infty \mathrm{H}_{2} \mathrm{O}$ in good agreement with the well-established ${ }^{10,12}$ value of $-\Delta H_{\mathrm{w}} \infty=55.82 \mathrm{~kJ} \mathrm{~mol}^{-1}$.

Unit of measurement. The results are expressed in absolute joule and refer to isothermal processes at $25.00^{\circ} \mathrm{C}$.

\section{MEASUREMENTS AND RESULTS}

The heat equivalent of the calorimetric system, determined by electric calibrations, was found to obey $\varepsilon_{V}=2.333+0.0230(V-100) \mathrm{J} \mathrm{ohm}^{-1}$ for all solutions used with $I=1 \mathrm{M}$.

For all the $\mathrm{S}$ solutions the heats of dilution were found to be negligible. Dilution of the T solutions in $1.00 \mathrm{M} \mathrm{NaClO}_{4}$, on the other hand, gave perceptible heat effects, though in all cases $<0.080 \mathrm{~J}$ per $\mathrm{cm}^{3}$ added $\mathrm{T}$ solution. Corresponding values of $Q_{\exp }$ and $Q_{\text {dil }}$ were always determined by analogous titration series. 
Table 2. Determination of the heats of formation for the hydrogen fluoride system.

For all the series: $V_{0}=100.0 \mathrm{~cm}^{3}$ and $V=\left(V_{0}+v\right) \mathrm{cm}^{2}$

a $\quad \circ$ S: $C_{\mathrm{H}}=0.06000 \mathrm{M}, \quad C_{\mathrm{NaClO}_{4}}=0.940 \mathrm{M}$.

T: $C_{\mathrm{NaF}}=0.4000 \mathrm{M}, \quad C_{\mathrm{NaClO}}=0.600 \mathrm{M}$.

$v / \mathrm{cm}^{8},-Q_{\exp } / \mathrm{J},-Q_{\text {corr }}^{\prime} / \mathrm{J}, \Delta Q_{\text {corr }}^{\prime} / \mathrm{J}$ :

$2.000,9.577,9.447,-0.076 ; 4.000,9.485,9.359,-0.074 ; 6.000,9.347,9.225,-0.075$;

$8.000,9.096,8.978,-0.083 ; 10.000,8.635,8.522,-0.121 ; 13.000,11.443,11.284,-0.058$; $16.000,7.807,7.656,0.008$;

$\mathrm{a}^{\mathrm{II}} \quad \mathrm{S} \mathrm{S}: C_{\mathrm{H}}=0.05172 \mathrm{M}, \quad C_{\mathrm{NaF}}=0.05517 \mathrm{M}$,

T: $C_{\mathrm{NaF}}=0.4000 \mathrm{M}, \quad C_{\mathrm{NaClO}}=0.600 \mathrm{M}$.

$v / \mathrm{cm}^{3},-Q_{\text {exp }} / \mathrm{J},-Q_{\text {corr }}^{\prime} / \mathrm{J}, \Delta Q_{\text {corr }}^{\prime}$

$3.000,3.836,3.698,-0.020 ; 6.000,1.895,1.765,-0.016 ; 9.000,1.167,1.046,-0.018$; $12.000,0.828,0.719,-0.029 ; 15.000,0.694,0.594,0.012$;

$\begin{array}{rlll}\mathrm{a}^{\mathrm{III}} \circ \mathrm{S}: & C_{\mathrm{H}}=0.04498 \mathrm{M}, & C_{\mathrm{NaF}}=0.1002 \mathrm{M}, \\ & \text { T: } C_{\mathrm{NaClO}}=0.855 \mathrm{M} . & \\ & C_{\mathrm{NaF}}=0.4000 \mathrm{M}, & C_{\mathrm{NaClO}}=0.600 \mathrm{M} .\end{array}$

$v / \mathrm{cm}^{3},-Q_{\text {exp }} / \mathrm{J},-Q_{\text {corr }}^{\prime} / \mathrm{J}, \Delta Q_{\text {corr }}^{\prime} / \mathrm{J}$ :

$3.000,0.502,0.410,-0.058 ; 6.000,0.439,0.359,-0.029$;

bI $\square$ S: $C_{\mathrm{H}}=0.04000 \mathrm{M}, \quad C_{\mathrm{NaClO}_{4}}=0.960 \mathrm{M}$.

T: $C_{\mathrm{NaF}}=0.4000 \mathrm{M}, \quad C_{\mathrm{NaClO}_{4}}=0.600 \mathrm{M}$.

$v / \mathrm{cm}^{8}-Q_{\text {exp }} / \mathrm{J},-Q_{\text {corr }}^{\prime} / \mathrm{J}, \Delta Q^{\prime}{ }_{\text {corr }} / \mathrm{J}$ :

$2.000,9.497,9.367,-0.029 ; 4.000,9.275,9.150,-0.025 ; 6.000,8.840,8.719,0.008$; $8.000,7.819,7.702,-0.024 ; 10.000,5.999,5.886,0.125 ; 13.000,4.660,4.501,0.096$; $16.000,1.979,1.828,-0.004$;

bII $\square$ S: $C_{\mathrm{H}}=0.03448 \mathrm{M}, \quad C_{\mathrm{NaF}}=0.05517 \mathrm{M}$, $C_{\mathrm{NaClO}}=0.910 \mathrm{M}$.

T: $C_{\mathrm{NaF}}=0.4000 \mathrm{M}, \quad C_{\mathrm{NaClO}_{4}}=0.600 \mathrm{M}$.

$v / \mathrm{cm}^{2},-Q_{\exp } / \mathrm{J},-Q_{\text {corr }}^{\prime} / \mathrm{J}, \Delta Q_{\text {corr }}^{\prime} / \mathrm{J}:$

$3.000,1.037,0.899,-0.054 ; 6.000,0.656,0.527,-0.079 ; 9.000,0.418,0.297,-0.146$; $12.000,0.351,0.242,-0.108 ; 15.000,0.259,0.158,-0.133$;

$\mathbf{c}^{\mathrm{I}}$

$\triangle$ S: $C_{\mathrm{H}}=0.02000 \mathrm{M}, \quad C_{\mathrm{NaClO}_{\mathrm{a}}}=0.980 \mathrm{M}$.

$\mathrm{T}: C_{\mathrm{NaF}}=0.4000 \mathrm{M}, \quad C_{\mathrm{NaClO}_{4}}=0.600 \mathrm{M}$.

$v / \mathrm{cm}^{3},-Q_{\text {exp }} / \mathrm{J},-Q_{\text {corr }}^{\prime} / \mathrm{J}, \Delta Q_{\text {corr }}^{\prime} / \mathrm{J}$ :

$1.000,4.577,4.510,-0.029 ; 2.000,4.414,4.351,-0.033 ; 3.000,4.092,4.029,-0.025$; $4.000,3.544,3.481,-0.008 ; 5.000,2.715,2.653,0.017 ; 6.000,1.787,1.728,0.009 ; 8.000$, $1.782,1.665,-0.059 ; 10.000,0.887,0.774,-0.004 ; 13.000,0.741,0.582,-0.033: 16.000$, $0.431,0.280,-0.092$;

cII $\triangle \mathrm{S}: \begin{aligned} & C_{\mathrm{H}}=0.01724 \mathrm{M}, \\ & C_{\mathrm{NaClO}}=0.928 \mathrm{M} .\end{aligned} C_{\mathrm{NaF}}=0.05517 \mathrm{M}$,

$\mathrm{T}: \stackrel{C_{\mathrm{NaFlO}}}{C_{\mathrm{NaF}}=0.4000 \mathrm{M},} \quad C_{\mathrm{NaClO}}=0.600 \mathrm{M}$.

$v / \mathrm{cm}^{3},-Q_{\text {exp }} / \mathrm{J},-Q^{\prime}{ }_{\text {corr }} / \mathrm{J}, \Delta Q^{\prime}{ }_{\text {corr }} / \mathrm{J}$ :

$3.000,0.318,0.180,-0.084 ; 6.000,0.255,0.126,-0.075 ; 9.000,0.230,0.109,-0.054$; 
Table 2. Continued.

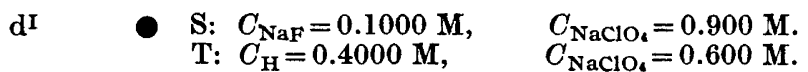

$v / \mathrm{cm}^{3},-Q_{\text {exp }} / \mathrm{J},-Q^{\prime}{ }_{\text {corr }} / \mathrm{J}, \Delta Q^{\prime}{ }_{\text {corr }} / \mathrm{J}:$

$3.000,15.405,15.259,0.046 ; 6.000,15.192,15.054,0.155 ; 9.000,14.828,14.698,0.146$;

$12.000,14.326,14.205,0.063 ; 15.000,13.669,13.556,=0.038$;

dII S: $C_{\mathrm{H}}=0.05217 \mathrm{M}, \quad C_{\mathrm{NaF}}=0.08696 \mathrm{M}$,

T: $C_{\mathrm{H}}^{C_{\mathrm{NaCl}}=0.4000 \mathrm{M},} \quad C_{\mathrm{NaClO}}=0.600 \mathrm{M}$.

$v / \mathrm{cm}^{3},-Q_{\text {exp }} / \mathrm{J},-Q_{\text {cort }}^{\prime} / \mathrm{J}, \Delta Q^{\prime}{ }_{\text {corr }} \mathrm{J}:$

$3.000,12.682,12.577,-0.092 ; 6.000,10.878,10.778,-0.088 ; 9.000,7.795,7.703,-0.029$; $12.000,4.460,4.372,0.050 ; 15.000,2.372,2.289,0.071$;

d III S: $C_{\mathrm{H}}=0.09754 \mathrm{M}, \quad C_{\mathrm{NaF}}=0.07561 \mathrm{M}$,

$\mathrm{T}: C_{\mathrm{H}}^{C_{\mathrm{NaClO}}}=0.4000 \mathrm{M}, \quad C_{\mathrm{NaClO}_{4}}=0.600 \mathrm{M}$.

$v / \mathrm{cm}^{3},-Q_{\text {exp }} / \mathrm{J},-Q_{\text {corr }}^{\prime} / \mathrm{J}, \Delta Q_{\text {corr }}^{\prime} / \mathrm{J}:$

$3.000,1.297,1.218,0.038 ; 6.000,0.774,0.699,0.021$;

eI $\quad$ S: $C_{\mathrm{NaF}}=0.05000 \mathrm{M}, \quad C_{\mathrm{NaClO}}=0.950 \mathrm{M}$,

$\mathrm{T}: C_{\mathrm{H}}=0.4000 \mathrm{M}, \quad C_{\mathrm{NaClO}_{4}}=0.600 \mathrm{M}$.

$v / \mathrm{cm}^{3},-Q_{\text {exp }} / \mathrm{J},-Q_{\text {corr }}^{\prime} / \mathrm{J}, \Delta Q^{\prime}{ }_{\text {corr }} / \mathrm{J}$ :

$3.000,14.732,14.585,0.004 ; 6.000,14.121,13.983,0.063 ; 9.000,12.749,12.619,-0.005$; $12.000,9.678,9.556,0.004 ; 15.000,5.092,4.979,0.113$;

eII D: $C_{\mathrm{H}}=0.05217 \mathrm{M}, \quad C_{\mathrm{NaF}}=0.04348 \mathrm{M}$,

T: $C_{\mathrm{H}}^{C_{\mathrm{NaClO}}=0.4000 \mathrm{M},} \quad C_{\mathrm{NaClO}_{4}}=0.600 \mathrm{M}$.

$v / \mathrm{cm}^{3},-Q_{\text {exp }} / \mathrm{J},-Q_{\text {corr }}^{\prime} / \mathrm{J}, \Delta Q_{\text {corr }}^{\prime} / \mathrm{J}$ :

$3.000,2.071,1.966,0.063 ; 6.000,0.950,0.849,0.046 ; 9.000,0.552,0.460,0.025 ; 12.000$, $0.381,0.293,0.029 ; 15.000,0.285,0.201,0.033$;

fI $\quad \Delta$ S: $C_{\mathrm{NaF}}=0.02500 \mathrm{M}, \quad C_{\mathrm{NaClO}}=0.975 \mathrm{M}$.

$\mathrm{T}: C_{\mathrm{H}}=0.4000 \mathrm{M}, \quad C_{\mathrm{NaClO}}=0.600 \mathrm{M}$.

$v / \mathrm{cm}^{3},-Q_{\text {exp }} / \mathrm{J},-Q^{\prime}{ }_{\text {corr }} / \mathrm{J}, \Delta Q^{\prime}{ }_{\text {corr }} / \mathrm{J}:$

$3.000,13.732,13.585,-0.050 ; 6.000,10.418,10.280,0.017 ; 9.000,4.046,3.916,0.054$; $12.000,1.264,1.142,0.042 ; 15.000,0.615,0.502,0.042$;

fII

$\triangle$ S: $C_{\mathrm{H}}=0.05217 \mathrm{M}, \quad C_{\mathrm{NaF}}=0.02174 \mathrm{M}$,

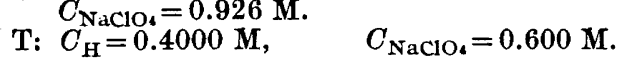

$v / \mathrm{cm}^{3},-Q_{\text {exp }} / \mathrm{J},-Q_{\text {corr }}^{\prime} / \mathrm{J}, \Delta Q_{\text {corr }}^{\prime} / \mathrm{J}:$

$3.000,0.322,0.218,-0.021 ; 6.000,0.280,0.180,0.042 ; 9.000,0.172,0.079,-0.004$;

The hydrogen fluoride system. Six different titration series on this system have been carried out, Table 2 . The titrations were performed according to the scheme B, and $V$ thus varied, between 100.0 and $118.0 \mathrm{~cm}^{3}$. Every series Acta Chem. Scand. 25 (1971) No. 9 
will therefore consist of several parts, divided by a removal of solution, $c f$. Table 2. In the series $\mathrm{a}, \mathrm{b}$, and $\mathrm{c}, \mathrm{S}$ and $\mathrm{T}$ had the following compositions:
$\mathrm{S}:\left\{\begin{array}{l}C_{\mathrm{H}} \\ \left(1.000-C_{\mathrm{H}}\right)\end{array}\right.$
$\mathrm{M} \mathrm{HaClO}_{4}$
$\mathrm{T}:\left\{\begin{array}{lll}0.400 & \mathrm{M} & \mathrm{NaF} \\ 0.600 & \mathrm{M} & \mathrm{NaClO}_{4}\end{array}\right.$

where $C_{\mathrm{H}}=0.060,0.040$, and 0.020 .

For the series $d, e$, and $f$ in Table $2, S$ and $T$ had the following compositions:
$\mathrm{S}:\left\{\begin{array}{l}C_{\mathrm{NaF}} \\ (1.000\end{array}\right.$
$\mathrm{M} \mathrm{NaF}$

where $C_{\mathrm{NaF}}=0.100,0.050$, and 0.025 .

For the calculations, the stability constants previously found, ${ }^{1}$ viz. $\delta_{1}=899 \mathrm{M}^{-1}$ and $\delta_{2}=3000 \mathrm{M}^{-2}$ were used. In Fig. $1 \Delta h_{v}$ is plotted versus $\bar{n}$.

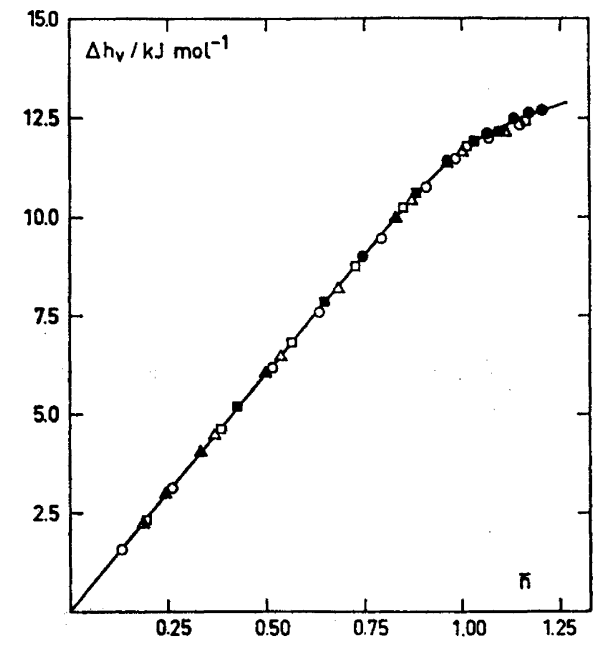

Fig. 1. The total molar enthalpy change, $\Delta h_{v}$, as a function of $\bar{n}$, for the hydrogen fluoride system, of. Table 2. Only half of the experimental points, chosen at random, have been plotted. The full-drawn curve has been calculated from the values of $\beta_{j}$ and $\Delta H_{j}{ }^{\circ}$ listed in Table 5.

Evidently no variation of $\Delta h_{v}$ with $C_{\mathrm{H}}$ can be discerned. This once more indicates that no polynuclear complexes were formed. Moreover, it is seen from the graph that all the six series coincide although three of them, a-c, have been started at low values of $\bar{n}$ and the other three, $d-f$, at high values of $\bar{n}$. The graphical and numerical methods of calculation gave the same result within the limits of error stated. The values of $\Delta H_{j}^{\circ}$ obtained by the computer are collected in Table 5. The errors given are three standard deviations. The differences $\Delta Q^{\prime}$ corr for all individual points are included in Table 2. The standard deviation $\sigma Q_{\text {corr }}^{\prime}$ was found to be equal to $0.062 \mathrm{~J}$.

The uranyl(VI) fluoride system. Three initial values of $C_{\mathrm{M}}$ were used. The solutions $\mathrm{S}$ and $\mathrm{T}$ had the compositions:
$\mathrm{S}:\left\{\begin{array}{l}C_{\mathrm{M}} \\ C_{\mathrm{H}} \\ (1 .\end{array}\right.$
$\mathrm{M} \mathrm{UO}_{2}\left(\mathrm{ClO}_{4}\right)_{2}$
$\mathrm{M} \mathrm{HClO}$
$\mathrm{T}:\left\{\begin{array}{lll}0.400 & \mathrm{M} & \mathrm{NaF} \\ 0.600 & \mathrm{M} & \mathrm{NaClO}_{4}\end{array}\right.$

where $C_{\mathrm{M}}=C_{\mathrm{H}}=0.050,0.030$, and 0.015 . 
Table 3. Determination of the heats of formation for the uranyl fluoride complexes.

For all the series: $V_{0}=100.0 \mathrm{~cm}^{3}$ and $V=\left(V_{0}+v\right) \mathrm{cm}^{3}$

aI $\quad$ S: $C_{\mathrm{M}}=C_{\mathrm{H}}=0.05000 \mathrm{M}, C_{\mathrm{NaClO}_{4}}=0.800 \mathrm{M}$.

$\mathrm{T}: C_{\mathrm{NaF}}=0.4000 \mathrm{M}, \quad C_{\mathrm{NaClO}}=0.600 \mathrm{M}$.

$v / \mathrm{cm}^{8},-Q_{\text {exp }} / \mathrm{J},-Q_{\text {corr }}^{\prime} / \mathrm{J}, \Delta Q_{\text {corr }}^{\prime} / \mathrm{J}$ :

$3.000,2.615,2.389,0.000 ; 6.000 .2 .736,2.527,0.029 ; 9.000,2.933,2.741,0.050 ; 12.000$, $3.121,2.941,-0.063 ; 15.000,3.556,3.393,-0.054$;

aII

○ S: $C_{\mathrm{M}}=C_{\mathrm{H}}=0.04348 \mathrm{M}$,

T. $C_{\mathrm{NaF}}=0.05217 \mathrm{M}, \quad C_{\mathrm{NaClO}_{4}}=0.774 \mathrm{M}$.

$v / \mathrm{cm}^{3},-Q_{\mathrm{exp}} / \mathrm{J},-Q_{\text {corr }}^{\prime} / \mathrm{J}, \Delta Q_{\text {corr }}^{\prime} / \mathrm{J}$ :

$C_{\mathrm{NaClO}}=0.600 \mathrm{M}$.

$3.000,4.251,4.100,0.105 ; 6.000,4.849,4.711,0.146 ; 9.000,5.251,5.121,0.092 ; 12.000$, $5.5 \cap 2,5.385,0.071 ; 15.000,5.515,5.406,0.050$;

aIII $\quad$ S: $C_{\mathrm{M}}=C_{\mathrm{H}}=0.03781 \mathrm{M}$,

$C_{\mathrm{NaF}}=0.09754 \mathrm{M}, \quad C_{\mathrm{NaClO}}=0.751 \mathrm{M}$.

$\mathrm{T}: C_{\mathrm{NaF}}=0.4000 \mathrm{M}, \quad C_{\mathrm{NaClO}}=0.600 \mathrm{M}$.

$v / \mathrm{cm}^{3},-Q_{\text {exp }} / \mathrm{J},-Q_{\text {corr }}^{\prime} / \mathrm{J}, \Delta Q_{\text {corr }}^{\prime} / \mathrm{J}:$

$3.000,5.243,5.138,0.046 ; 6.000,4.615,4.519,0.046 ; 9.000,3.745,3.653,0.059 ; 12.000$, 2.774, 2.686, 0.092; $15.000,1.874,1.791,0.134$;

aIV O S: $C_{\mathrm{M}}=C_{\mathrm{H}}=0.03288 \mathrm{M}$,

$C_{\mathrm{NaF}}=0.1370 \mathrm{M}, \quad C_{\mathrm{NaClO}}=0.731 \mathrm{M}$.

$\mathrm{T}: C_{\mathrm{NaF}}=0.4000 \mathrm{M}, \quad C_{\mathrm{NaClO}}=0.600 \mathrm{M}$.

$v / \mathrm{cm}^{3},-Q_{\exp } / \mathrm{J},-Q^{\prime}{ }_{\text {corr }} / \mathrm{J}, \Delta Q^{\prime}{ }_{\text {corr }} / \mathrm{J}$ :

$3.000,0.874,0.795,-0.109 ; 6.000,0.494,0.414,-0.013 ; 9.000,0.351,0.276,0.084$;

$12.000,0.163,0.088,-0.004 ; 15.000,0.130,0.059,0.004$;

$\mathrm{a}^{\mathbf{v}}$

○ $\mathrm{S}: C_{\mathrm{M}}=C_{\mathrm{H}}=0.02859 \mathrm{M}$,

$\begin{array}{ll}C_{\mathrm{NaF}}=0.1713 \mathrm{M}, & C_{\mathrm{NaClO}}=0.714 \mathrm{M} . \\ C_{\mathrm{NaF}}=0.4000 \mathrm{M}, & C_{\mathrm{NaClO}}=0.600 \mathrm{M} .\end{array}$

$v / \mathrm{cm}^{3}-Q_{\text {cxp }} / \mathrm{J},-Q_{\text {corr }}^{\prime} / \mathrm{J}, \Delta Q_{\text {corr }}^{\prime} / \mathrm{J}$ :

$3.000,0.050,-0.021,-0.063 ; 6.000,0.021,-0.050,-0.088 ; 9.000,0.025,-0.046$, $-0.092$ bI $\square$ S: $\begin{aligned} & C_{\mathrm{M}}=C_{\mathrm{H}}=0.03000 \mathrm{M}, \\ & C_{\mathrm{NaClO}}=0.880 \mathrm{M} .\end{aligned}$

$\mathrm{T}: C_{\mathrm{NaF}}=0.4000 \mathrm{M}, \quad C_{\mathrm{NaClO}}=0.600 \mathrm{M}$.

$v / \mathrm{cm}^{3},-Q_{\text {exp }} / \mathrm{J},-Q_{\text {corr }}^{\prime} / \mathrm{J}, \Delta Q_{\text {corr }}^{\prime} / \mathrm{J}:$

$2.000,1.724,1.569,-0.025 ; 4.000,1.862,1.715,0.033 ; 6.000,2.029,1.887,0.046 ; 8.000$, $2.167,2.033,-0.071 ; 10.000,2.431,2.305,-0.151 ; 13.000,4.581,4.406,0.033 ; 16.000$, $5.188,5.025,0.000$;

bII S: $\begin{aligned} & C_{\mathrm{M}}=C_{\mathrm{H}}=0.02586 \mathrm{M}, \\ & C_{\mathrm{NaF}}=0.05517 \mathrm{M},\end{aligned}$

T: $\begin{array}{ll}C_{\mathrm{NaF}}=0.05517 \mathrm{M}, & C_{\mathrm{NaClO}}=0.841 \mathrm{M} . \\ C_{\mathrm{NaClO}}=0.600 \mathrm{M} & =0.4000 \mathrm{M},\end{array}$

$v / \mathrm{cm}^{3},-Q_{\text {exp }} / \mathrm{J},-Q^{\prime}{ }_{\text {corr }} / \mathrm{J}, \Delta Q_{\text {corr }}^{\prime} / \mathrm{J}:$

$3.000,5.314,5.167,-0.092 ; 6.000,4.795,4.657,-0.167 ; 9.000,3.770,3.644,-0.092$; $12.000,2.502,2.389,0.000 ; 15.000,1.372,1.264,0.012$;

Acta Chem. Scand. 25 (1971) No. 9 
Table 3. Continued.

bIII

S: $C_{\mathrm{M}}=C_{\mathrm{H}}=0.2249 \mathrm{M}$, $C_{\mathrm{MaF}}=0.1001 \mathrm{M}, \quad C_{\mathrm{NaClO}}=0.810 \mathrm{M}$.

$\mathrm{T}: C_{\mathrm{NaF}}=0.4000 \mathrm{M}, \quad C_{\mathrm{NaClO}}=0.600 \mathrm{M}$.

$v_{i}^{\prime} \mathrm{cm}^{3},-Q_{\text {exp }} / \mathrm{J},-Q_{\text {corr }}^{\prime} / \mathrm{J}, \Delta Q_{\text {corr }}^{\prime} / \mathrm{J}:$

$3.000,0.649,0.548,0.004 ; 6.000,0.322,0.226,0.021 ; 9.000,0.201,0.109,0.025 ; 12.000$, $0.113,0.025,-0.021$;

c $^{\mathrm{I}}$

$\triangle \mathrm{S}: C_{\mathrm{M}}=C_{\mathrm{H}}=0.01500 \mathrm{M}$,

$C_{\mathrm{NaClO}}=0.940 \mathrm{M}$,

$\mathrm{T}: C_{\mathrm{NaF}}=0.4000 \mathrm{M}$,

$$
C_{\mathrm{NaClO}}=0.600 \mathrm{M}
$$

$v / \mathrm{cm}^{3},-Q_{\mathrm{cxp}} / \mathrm{J},-Q_{\text {corr }}^{\prime} / \mathrm{J}, \Delta Q_{\text {corr }}^{\prime} / \mathrm{J}$ :

$1.000,0.849,0.770,-0.025 ; 2.000,0.937,0.862,0.021 ; 3.000,1.000,0.925,0.008 ; 4.000$, $1.138,1.067,0.021 ; 5.000,1.176,1.105,-0.109 ; 7.000,2.900,2.761,-0.176 ; 9.000$, $3.439,3.310,-0.042 ; 11.000,3.272,3.146,-0.071 ; 13.000,2.594,2.481,-0.054 ; 15.000$, $1.736,1.623,-0.008$;

cII

$$
\triangle \mathrm{S}: C_{\mathrm{M}}=C_{\mathrm{H}}=0.01304 \mathrm{M},
$$

$\mathrm{T}: C_{\mathrm{NaF}}=0.4000 \mathrm{M}, \quad C_{\mathrm{NaClO}}=0.600 \mathrm{M}$.

$v / \mathrm{cm}^{8},-Q_{\exp } / J,-Q_{\text {corr }}^{\prime} / J, \Delta Q_{\text {corr }}^{\prime} / J$ :

$3.000,1.146,0.996,-0.071 ; 6.000,0.464,0.326,0.017 ; 9.000,0.226,0.096,0.000 ; 12.000$ ' $0.163,0.046,0.008 ; 15.000,0.138,0.029,0.004$;

The titrations have been performed according to the scheme B. The results are found in Table 3. The experimentally measured heat changes, $Q_{\text {exp }}$, are in fact mainly due to the reactions between protons and fluoride ions. The data just determined for this system allow, however, a very precise calculation of the heat change due to uranyl complex formation. From Fig. 2

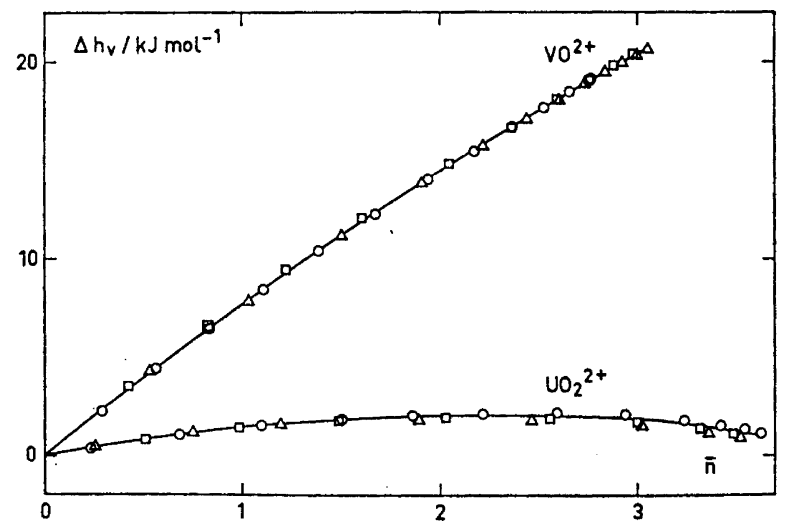

Fig. 2. The total molar enthalpy change, $\Delta h_{v}$, as a function of $\bar{n}$, for the uranyl(VI) and vanadyl(IV) fluoride systems, $c f$. Tables 3 and 4 . For the uranyl(VI) fluoride system only half of the experimental points, chosen at random, have been plotted. The fulldrawn curves have been calculated from the values of $\beta_{j}$ and $\Delta H_{j}^{\circ}$ listed in Table 5 . 
it can be seen that there is no significant variation of $\Delta h_{v}$ with $C_{\mathrm{M}}$, implying that no polynuclear species are present. The graphical method of calculation and the least-squares program gave $\Delta H_{j}^{\circ}$-values that agreed very well. The results of the latter method are tabulated in Table 5. The standard deviation $\sigma Q_{\text {corr }}^{\prime}$ was assigned a value of $0.073 \mathrm{~J}$ and the values of $\Delta Q_{\text {corr }}^{\prime}$ for all individual points are given in Table 3.

The vanadyl(IV) fluoride system. Titrations were performed with three different initial values of $C_{\mathrm{M}}$, according to the scheme $\mathrm{A}$. In all series, the value of $C_{\mathrm{H}}$ was the same as that of $C_{\mathrm{M}}$. The solutions $\mathrm{S}$ and $\mathrm{T}$ were composed according to:

$$
\mathrm{S}:\left\{\begin{array}{ll}
C_{\mathrm{M}} & \mathrm{M} \mathrm{VO}\left(\mathrm{ClO}_{4}\right)_{2} \\
C_{\mathrm{H}}^{\mathrm{HCOO}_{4}} & \mathrm{M} \mathrm{HClO} \\
\left(1.000-3 C_{\mathrm{M}}-C_{\mathrm{H}}\right) & \mathrm{M} \mathrm{NaClO}_{4}
\end{array} \quad \mathrm{~T}:\left\{\begin{array}{l}
0.4043 \mathrm{M} \mathrm{NaF} \\
0.596 \mathrm{M} \mathrm{NaClO}
\end{array}\right.\right.
$$

The values of $Q_{\exp }$ and $Q_{\text {corr }}^{\prime}$ arrived at are given in Table 4. The titrations could not be pursued to values of $[\mathrm{L}]>90 \mathrm{mM}$ (corresponding to a value of $\bar{n} \approx 3$ ) as a precipitation of the vanadyl $(\mathrm{IV})$ fluoride $\mathrm{Na}_{3} \mathrm{VOF}_{5}$ occurred. The fourth complex is therefore formed only in minor amounts within the range of [L] available, which means that the accuracy of $\Delta \mathrm{H}_{4}{ }^{\circ}$ is not very

Table 4. Determination of the heats of formation for the vanadyl fluoride complexes.

For all the series: $V=V_{0}=100.24 \mathrm{~cm}^{3}$

$$
\begin{array}{lll}
\text { a } \quad \mathrm{S}: C_{\mathrm{M}}=0.02964 \mathrm{M}, & C_{\mathrm{H}}=0.03000 \mathrm{M}, \\
& C_{\mathrm{NaClO}}=0.881 \mathrm{M} . & \\
& \mathrm{T}: C_{\mathrm{NaF}}=0.4043 \mathrm{M}, & C_{\mathrm{NaClO}}=0.596 \mathrm{M} .
\end{array}
$$

$v / \mathrm{cm}^{2},-Q_{\text {exp }} / \mathrm{J},-Q^{\prime}{ }_{\text {corr }} / \mathrm{J}, \Delta Q^{\prime}{ }_{\text {corr }} / \mathrm{J}$ :

$3.000,11.171,10.941,0.012 ; 6.000,11.238,11.016,0.038 ; 9.000,11.054,10.837,0.042$; $12.000,10.502,10.297,0.084 ; 15.000,9.351,9.150,-0.025 ; 18.000,7.824,7.632,0.000 ;$ $21.000,6.176,5.991,-0.008 ; 24.000,4.653,4.477,-0.038 ; 27.000,3.594,3.431,0.037$; $30.000,2.778,2.623,0.029 ; 33.000,2.218,2.071,0.038 ; 36.000,1.799,1.657,0.050$;

b

S: $C_{\mathrm{M}}=0.01976 \mathrm{M}, \quad C_{\mathrm{H}}=0.01776 \mathrm{M}$,

$C_{\mathrm{NaClO}}=0.923 \mathrm{M}$.

T: $C_{\mathrm{NaF}}^{\mathrm{NaClO}}=0.4043 \mathrm{M}, \quad C_{\mathrm{NaClO}_{4}}=0.596 \mathrm{M}$.

$v / \mathrm{cm}^{8},-Q_{\text {exp }} / \mathrm{J},-Q_{\text {corr }}^{\prime} / \mathrm{J}, \Delta Q^{\prime}{ }_{\text {corr }} / \mathrm{J}$ :

$3.000,10.975,10.749,0.021 ; 6.000,10.791,10.573,0.059 ; 9.000,9.690,9.485,0.042$; $12.000,7.678,7.481,0.004 ; 16.000,6.690,6.439,-0.084 ; 20.000,4.105,3.862,-0.033$; $24.000,2.741,2.515,0.021 ; 28.000,1.962,1.753,0.025 ; 32.000,1.431,1.243,-0.012 ; 36.000$, $1.146,0.971,-0.004 ; 40.000,0.870,0.707,-0.042$;

c

$$
\begin{array}{rll}
\triangle \mathrm{S}: & C_{\mathrm{M}}=0.01486 \mathrm{M}, & C_{\mathrm{H}}=0.01504 \mathrm{M}, \\
& C_{\mathrm{NaClo}}=0.940 \mathrm{M} . & \\
\mathrm{T}: & C_{\mathrm{NaF}}=0.4043 \mathrm{M}, & C_{\mathrm{NaClO}}=0.596 \mathrm{M} .
\end{array}
$$

$v / \mathrm{cm}^{8},-Q_{\text {exp }} / \mathrm{J},-Q_{\text {corr }}^{\prime} / \mathrm{J}, \Delta Q_{\text {corr }}^{\prime} / \mathrm{J}:$

$3.000,10.912,10.678,-0.100 ; 6.000,10.226,10.004,-0.167 ; 9.000,8.305,8.092,-0.008$; $12.000,5.540,5.335,0.088 ; 15.000,3.402,3.205,-0.004 ; 18.000,2.301,2.113,0.029$; $21.000,1.628,1.448,-0.012 ; 24.000,1.272,1.096,0.013 ; 27.000,0.971,0.808,-0.054$; $30.000,0.803,0.649,-0.025 ; 33.000,0.665,0.519,-0.042 ; 36.000,0.536,0.393,-0.063$;

Acta Chem. Scand. 25 (1971) No. 9 
high. The $\Delta h_{v}$ functions for the three series are plotted versus $\bar{n}$ in Fig. 2. As the series coincide within the experimental errors there is no indication of polynuolear complexes. This agrees with the result found in the potentiometric investigation of the same system. ${ }^{1}$ Graphical and computer evaluation of the data gave the same results. The values of $\Delta H_{j}^{\circ}$ presented in Table 5 are those obtained by the computer. In Table 4 the calculated values of $\Delta Q_{\text {corr }}^{\prime}$ for all measured points are also reported. The standard deviation $\sigma Q_{\text {corr }}^{\prime}$ was found to be $0.052 \mathrm{~J}$.

Table 5. The stability constants used and the computed values of free energy, enthalpy and entropy changes for the stepwise reactions of the three fluoride systems. The limits of error given correspond to three standard deviations or to estimated errors.

\begin{tabular}{|c|r|c|c|c|}
\hline Acceptor & & $\mathrm{H}^{+}$ & $\mathrm{UO}_{2}{ }^{2+}$ & $\mathrm{VO}^{2+}$ \\
\hline & $j=1$ & $899 \pm 5$ & $(3.43 \pm 0.04) \times 10^{4}$ & $(2.35 \pm 0.03) \times 10^{2}$ \\
$\beta_{j} / \mathrm{M}^{-i}$ & 2 & $3000 \pm 100$ & $(9.5 \pm 0.2) \times 10^{7}$ & $(5.5 \pm 0.1) \times 10^{5}$ \\
& 3 & - & $(2.60 \pm 0.07) \times 10^{10}$ & $(1.97 \pm 0.07) \times 10^{7}$ \\
& 4 & - & $(7.8 \pm 0.5) \times 10^{11}$ & $(1.2 \pm 0.1) \times 10^{8}$ \\
$-\Delta G_{j}^{\circ}$ & 1 & $16.86 \pm 0.02$ & $25.89 \pm 0.03$ & $19.24 \pm 0.03$ \\
$\mathrm{~kJ} \mathrm{~mol}^{-1}$ & 2 & $2.99 \pm 0.08$ & $19.65 \pm 0.07$ & $13.53 \pm 0.06$ \\
& 3 & - & $13.91 \pm 0.09$ & $8.87 \pm 0.10$ \\
& 4 & - & $8.43 \pm 0.17$ & $4.48 \pm 0.24$ \\
$-\Delta H_{j}^{\circ}$ & 1 & $-12.17 \pm 0.04$ & $-1.70 \pm 0.08$ & $-7.86 \pm 0.10$ \\
$\mathrm{~kJ} \mathrm{~mol}^{-1}$ & 2 & $-2.03 \pm 0.28$ & $-0.40 \pm 0.17$ & $-6.47 \pm 0.25$ \\
& 3 & - & $-0.25 \pm 0.25$ & $-5.8 \pm 0.4$ \\
& 4 & - & $2.06 \pm 0.35$ & $-6.1 \pm 1.4$ \\
$\Delta S_{j}^{\circ}$ & 1 & $97.4 \pm 0.2$ & $92.5 \pm 0.3$ & $90.9 \pm 0.4$ \\
$\mathrm{~J} \mathrm{~mol}^{-1} \mathrm{~K}^{-1}$ & 2 & $19.8 \pm 0.9$ & $67.2 \pm 0.6$ & $67.1 \pm 0.8$ \\
& 3 & - & $47.5 \pm 0.9$ & $49.2 \pm 1.4$ \\
\hline
\end{tabular}

\section{DISCUSSION}

The free energy, enthalpy and entropy changes found for the stepwise formation of the investigated complex systems are collected in Table 5. The limits of error refer either to three standard deviations, as given by the computer, or to estimated maximum errors from the graphical evaluation methods.

The value of $\Delta H_{1}^{\circ}$ found here for the hydrogen fluoride system agrees very well with that quoted before as the most probable value for $I=0.5 \mathrm{M} .{ }^{7}$ This is in accord with the observation of Gerding and Jönsson ${ }^{13}$ that the enthalpy changes do not vary much with the ionic strength in the range $0.5<I<1$. On the other hand the difference between the $\Delta H_{1}^{\circ}$ value for the uranyl fluoride system now obtained and the value $\left(-10 \mathrm{~kJ} \mathrm{~mol}^{-1}\right)$ found at an ionic strength of $2.00 \mathrm{M}$ by Day and Powers ${ }^{5}$ is rather large. 
The discrepancy probably depends on the fact that the temperature coefficient method does not work well in this case ( $c f$. p. 3471).

The complex formation of the three fluoride systems investigated is entropy stabilized. The reactions are all endothermic with the exception of $\Delta \mathrm{H}_{4}^{\circ}$ for the uranyl fluoride system. Especially for the hydrogen and vanadyl fluoride systems, the enthalpy changes are highly counteracting complex formation. This behaviour is expected as the ligands and acceptors involved are all quite hard.7,14

The uranyl and vanadyl fluoride systems have almost the same entropy changes for the first three reaction steps, while corresponding enthalpy changes are approximately $6 \mathrm{~kJ} \mathrm{~mol}^{-1}$ more favourable for the uranyl complexes, causing their increased strength relative to the vanadyl complexes.

For each of the fluoride systems, the $\Delta H_{j}^{\circ}$ and $\Delta S_{j}^{\circ}$ values decrease progressively as $j$ increases. This certainly depends upon that the hydration decreases for each consecutive complex. Consequently, less water is set free for each step. ${ }^{15}$ The trend is especially marked in the hydrogen fluoride system where both $\Delta H_{j}^{\circ}$ and $\Delta S_{1}^{\circ}$ decrease very much between the first and second step.

Further discussion will be postponed until the complete result of this investigation has been reported.

Acknowledgements. We are most grateful to Drs. Ingmar Grenthe and Heikki Ots who most generously shared their great experience of calorimetric precision measurements with us. Their help has been extremely valuable. The calorimeter was built by Mr. Evert Hedenstierna, Chief Mechanic, and Mr. Sune Jönsson. Its good function is very much due to their skill and care.

\section{REFERENCES}

1. Ahrland, S. and Kullberg, L. 25 (1971) 3457.

2. McAuley, A. and Nancollas, G. H. J. Chem. Soc. 1963989.

3. Jones, A. D. and Choppin, G. R. Actinides Rev. 1 (1969) 311.

4. Schlyter, K. and Sillén, L. G. Acta Chem. Scand. 13 (1959) 385.

5. Day, Jr., R. A. and Powers, R. M. J. Am. Chem. Soc. 76 (1954) 3895.

6. Hepler, L. G., Jolly, W. L. and Latimer, W. M. J. Am. Chem. Soc. 75 (1953) 2809.

7. Ahrland, S. Helv. Chim. Acta 50 (1967) 306.

8. Sillén, L. G. Acta Chem. Scand. 18 (1964) 1085.

9. Ingri, N. and Sillén, L. G. Arkiv Kemi 23 (1964) 97.

10. Grenthe, I., Ots, H. and Ginstrup, O. Acta Chem. Scand. 24 (1970) 1067.

11. Wagman, D. D., Bailey, S. M. and Schumm, R. H. Selected Values of Chemical Thermodynamic Properties, N.B.S. Technical Note 270-3 Jan. 1968.

12. Gerding, P., Leden, I. and Sunner, S. Acta Chem. Scand. 17 (1963) 2190.

13. Gerding, P. and Jönsson, I. Acta Chem. Scand. 22 (1968) 2247.

14. Ahrland, S. Struct. Bonding (Berlin) 5 (1968) 118.

15. Ahrland, S. Section Lecture XIII. Intern. Conf. Coord. Chem. Cracow-Zakopane, Poland 1970. In press.

Received February 12, 1971. 